ASTHMA

\title{
Maternal age of menarche is not associated with asthma or atopy in prepubertal children
}

\author{
A Maitra, A Sherriff, K Northstone, D Strachan, the ALSPAC Study Team, \\ A J Henderson
}

See end of article for authors' affiliations

......................

Correspondence to: Dr A J Henderson, Department of Respiratory Medicine, Bristol Royal Hospital for Children Bristol BS2 8BJ, UK. A.J.Henderson@bris.ac.uk

Received 2 November 2004

Accepted 11 July 2005

Published Online First

29 July 2005
Background: Maternal sex hormones in pregnancy can theoretically influence the developing fetal immune system and modulate the subsequent development of atopic disorders. Early onset of menarche has been linked to increased oestrogen levels in adult women. A study was undertaken to examine the association between early onset menarche in pregnant women and asthma and atopic status of their children at 7 years of age.

Methods: The Avon Longitudinal Study of Parents and Children (ALSPAC) is a longitudinal birth cohort study in which pregnant women, resident in Avon (UK), were recruited on the basis of an expected date of delivery between 1 April 1991 and 31 December 1992. Maternal age at menarche was assessed from prenatal questionnaires administered to the women. Clinical outcomes in the children were based on mothers' responses to self-completion questionnaires and included asthma, eczema, and hay fever. The atopic status of the child was objectively assessed by skin prick tests to a panel of common aeroallergens at the age of 7 years. Analyses used multivariable logistic regression with a diverse range of possible confounders.

Results: Complete data were available on 5765 woman and child pairs. The prevalence of ever reported asthma to 7 years was $20.4 \%$, eczema $58.6 \%$, hay fever $12.1 \%$, and atopy (defined as any positive (>2 mm weal) response) was present in $20.6 \%$. There were no significant differences in mean age of menarche between mothers of children with and without each of the primary outcomes. Adjusted odds ratios $(95 \% \mathrm{Cl})$ for the latest age of menarche (16+ years) compared with the lowest $(<12$ years) reference group were 1.41 (1.00 to 1.99$)$ for asthma, 0.98 (0.73 to 1.91) for eczema, 0.95 (0.62 to 1.44$)$ for hay fever, and 0.98 (0.68 to 1.42$)$ for atopy.

Conclusion: No consistent association was found between maternal age at menarche and asthma, eczema, hay fever or atopy in their children during early childhood.
A sthma and allergy in childhood are disorders of important public health concern. ${ }^{12}$ The prevalence of asthma and allergy has risen in many industrialised countries and the reasons for this increase are still unexplained..$^{3-6}$ Change in the environment coupled with individual susceptibility may explain some of these changes. Recently, considerable interest has been generated about the role of early life factors that may influence the subsequent development of atopy. In particular, exposure of the immature fetal immune system to excessive maternal oestrogen has been postulated to be associated with the subsequent development of atopy in the offspring. ${ }^{78} \mathrm{Xu}$ et al have demonstrated in a Finnish birth cohort that early age of maternal menarche, a surrogate marker for persistently raised levels of oestrogen, was associated with a higher prevalence of atopy among their offspring at the age of 31 years. ${ }^{9}$ However, outcome assessment at a long interval may be confounded by many factors that are operating during this time. Further evidence of an effect of age of menarche on atopic outcomes came from a large epidemiological study in Denmark in which early onset menarche was associated with an increased risk of allergic rhinitis in adult women. ${ }^{10}$ However, a recent case control study in 129 asthmatic children did not find any association between maternal sex hormones in early pregnancy and the onset of allergic diseases in early childhood. ${ }^{11}$ With this background, we have examined whether atopy and allergic diseases are more prevalent in children from a contemporary birth cohort whose mothers experienced early onset of menarche.

\section{METHODS}

The Avon Longitudinal Study of Parents and Children (ALSPAC) is a longitudinal birth cohort study of the determinants of development, health, and disease during childhood and beyond. Pregnant women were recruited to the study on the basis of an expected date of delivery between 1 April 1991 and 31 December 1992 and residence in one of the three Bristol based health districts of Avon in the south west of England. This study has been described elsewhere ${ }^{12}$ and more information can be obtained from the study website (http://www.alspac.bris.ac.uk). In brief, a total of 14541 women were enrolled during pregnancy, resulting in 14062 live births (of whom $7272(51.7 \%)$ were boys and $6790(48.3 \%)$ were girls). Of these, 13971 children survived to 1 year. It was estimated that $85-90 \%$ of eligible mothers were enrolled in the study.

Data were collected from questionnaires completed by the parents, medical records, biological samples, and regular physical and psychological examinations. Pregnant women participating in the study completed four questionnaires during their pregnancy. Postnatally, questionnaires relating to the child were administered at $1,6,15,18$, 24, 30 months and at 6 monthly intervals thereafter, and to the study mothers and their partners on an annual basis. From 7 years of age onwards the entire ALSPAC cohort has been invited to attend annual research clinics for detailed physical and psychological observations. Approximately 8000 children from the total population have attended $(\sim 58 \%)$. 


\begin{tabular}{|c|c|c|c|c|}
\hline $\begin{array}{l}\text { Maternal age at } \\
\text { menarche (years) }\end{array}$ & $\begin{array}{l}\text { Doctor diagnosed } \\
\text { asthma }(20.4 \%)\end{array}$ & $\begin{array}{l}\text { Ever reported } \\
\text { eczema }(58.6 \%)\end{array}$ & $\begin{array}{l}\text { Ever reported hay } \\
\text { fever }(12.1 \%)\end{array}$ & $\begin{array}{l}\text { Atopy (SPT weal } \\
\geqslant 2 \mathrm{~mm})(20.6 \%)\end{array}$ \\
\hline$<12$ & $309 / 1356(22.8 \%)$ & $604 / 1051$ (57.5\%) & $146 / 1167(12.5 \%)$ & $224 / 1098$ (20.4\%) \\
\hline 12 & $284 / 1518(18.7 \%)$ & $712 / 1194(59.6 \%)$ & $167 / 1334(12.5 \%)$ & $239 / 1223(19.5 \%)$ \\
\hline 13 & $429 / 2068(20.7 \%)$ & $979 / 1640(59.7 \%)$ & $206 / 1812(11.4 \%)$ & $377 / 1726(21.8 \%)$ \\
\hline 14 & $230 / 1225$ (18.8\%) & $584 / 979(59.7 \%)$ & $134 / 1071$ (12.5\%) & $187 / 999(18.7 \%)$ \\
\hline 15 & $116 / 591$ (19.6\%) & $264 / 451(58.5 \%)$ & $70 / 509(13.8 \%)$ & $94 / 487(19.3 \%)$ \\
\hline $16+$ & $86 / 338(25.4 \%)$ & $146 / 262(55.7 \%)$ & $32 / 295$ (10.8\%) & $54 / 259(20.8 \%)$ \\
\hline$\chi^{2}$ (p value) & $15.00(0.010)$ & $2.92(0.713)$ & $3.15(0.677)$ & $4.87(0.432)$ \\
\hline $\mathrm{p}$ for trend & 0.729 & 0.985 & 0.903 & 0.733 \\
\hline $\begin{array}{l}\text { Mean (SD) } \\
\text { difference (years) }\end{array}$ & $0.042(0.048)$ & $0.004(0.041)$ & $0.018(0.058)$ & $0.020(0.063)$ \\
\hline$t$ ( $p$ value) & $0.86(0.389)$ & $0.10(0.918)$ & $0.30(0.762)$ & $0.37(0.709)$ \\
\hline
\end{tabular}

The ALSPAC study has approval from the local research ethics committees covering the study area (United Bristol Healthcare NHS Trust \& North Bristol NHS Trust).

\section{Questionnaire based data}

In one of the prenatal questionnaires the study women were asked how old they were when they started their periods. Space was provided for a numerical response with the option of reporting they had not had periods or that they could not remember.

When the children were aged 91 months, mothers were asked to report if a doctor had ever diagnosed their child with asthma. A diagnosis of eczema was based on positive responses to a question about dry, itchy rash in the joints or creases sent to mothers annually from 6 months to 81 months and a positive response to a question at 81 months and 91 months about eczema in the previous 12 months. All positive responses were grouped as "ever" eczema. Children were classified as having had hay fever if their mothers responded positively to questions about pollen allergy at 54 months and 81 months or to their child having hay fever in the past 12 months at 81 months and 91 months. Positive responses were grouped as "ever" hay fever.

\section{Atopic status of children}

At the age of 7 years children underwent skin prick testing against a panel of commercial aeroallergen extracts (ALKAbelló, Horshølm, Denmark) to which the UK population is commonly sensitised, histamine $1 \%$ positive control and diluent negative control. The testing was performed by a team of 11 staff who were trained in the technique by an allergy nurse specialist. Briefly, a drop of allergen extract was placed on the skin and pricked through with a sterile lancet. A different lancet was used for each allergen. The skin was then gently blotted dry taking care not to contaminate adjacent skin prick sites. Responses were assessed after 20 minutes by measuring the largest weal diameter and the diameter perpendicular to this. Atopy was defined as a mean weal diameter of $\geqslant 2 \mathrm{~mm}$ to one or more of cat, mixed grass and house dust mite (Der $p$ I) with a zero response to the negative control to minimise false positives. The inter-tester performance was evaluated by comparing positive ( $1 \%$ histamine) weal sizes.

\section{Potential confounding factors}

Information on maternal age at delivery and season of birth of the child was collected from clinical records. Maternal body mass index (BMI) before pregnancy was obtained from self-reported height and weight, and parity and history of allergies were obtained from self-report questionnaires administered during pregnancy. Maternal highest educational attainment and maternal smoking during pregnancy were also ascertained from questionnaires during the study pregnancy. The child's BMI was measured during the same clinic at which the allergy tests were performed.

\section{Statistical analysis}

All statistical analyses were carried out using SPSS for Windows (Version 10.0.0). Univariable analyses of the association between maternal age at menarche and atopy in the children were carried out using contingency tables and $\chi^{2}$ tests for heterogeneity and linear trend. Multivariable logistic regression models were used to evaluate the association between maternal age at menarche (independent variable) and atopy in the children (dependent variable), while accounting for a number of potentially important confounding variables: sex of the child, maternal age at delivery $(<20$, 20-24, 25-30, 31-35, and 35+ years), maternal BMI before pregnancy (obese/non-obese), maternal education (5 point scale ranging from none/minimal to university degree), maternal parity $(0,1,2+)$, smoking during pregnancy (number of cigarettes per day), maternal history of allergy (yes/no), and child's BMI (quintiles), birth weight (quintiles), and month of birth. As a significant difference was detected in histamine responses between skin testers, tester was included as an independent variable in analyses of atopic status. The likelihood ratio statistic was used to determine levels of significance.

\section{RESULTS}

Complete data were available on 5765 women and child pairs. The cumulative percentage of women reporting

Table 2 Unadjusted and adjusted odds ratios for maternal age at menarche and asthma

\begin{tabular}{lll}
\hline $\begin{array}{l}\text { Maternal age } \\
\text { at menarche } \\
\text { (years) }\end{array}$ & $\begin{array}{l}\text { Unadjusted OR }(95 \% \mathrm{Cl}) \\
\mathbf{n = 7 0 9 6}\end{array}$ & $\begin{array}{l}\text { Adjusted OR }(95 \% \mathrm{Cl}) * \\
\mathbf{n}=5103\end{array}$ \\
\hline$<12$ & 1.00 (reference) & 1.00 (reference) \\
12 & $0.78(0.65$ to 0.93$)$ & $0.81(0.65$ to 1.01$)$ \\
13 & $0.89(0.75$ to 1.05$)$ & $0.97(0.79$ to 1.19$)$ \\
14 & $0.78(0.65$ to 0.95$)$ & $0.90(0.72$ to 1.14$)$ \\
15 & $0.83(0.65$ to 1.05$)$ & $0.82(0.61$ to 1.11$)$ \\
$16+$ & $1.16(0.88$ to 1.52$)$ & $1.41(1.00$ to 1.99$)$ \\
$p$ value & 0.011 & 0.026 \\
\hline
\end{tabular}

*Adjusted for sex, maternal education, maternal age at delivery, maternal allergy history, maternal smoking in pregnancy, maternal BMI (continuous), child birth weight (continuous), child BMI (continuous). 
Table 3 Unadjusted and adjusted odds ratios for maternal age at menarche and eczema

\begin{tabular}{lll}
\hline $\begin{array}{l}\text { Maternal age } \\
\text { at menarche } \\
\text { (years) }\end{array}$ & $\begin{array}{l}\text { Unadjusted OR }(95 \% \mathrm{Cl}) \\
\mathbf{n}=\mathbf{5 5 7 7}\end{array}$ & $\begin{array}{l}\text { Adjusted OR }(95 \% \mathrm{Cl}) * \\
\mathbf{n = 5 1 4 6}\end{array}$ \\
\hline$<12$ & 1.00 (reference) & 1.00 (reference) \\
12 & $1.09(0.92$ to 1.29$)$ & $1.10(0.92$ to 1.31$)$ \\
13 & $1.10(0.94$ to 1.28$)$ & $1.11(0.94$ to 1.31$)$ \\
14 & $1.09(0.92$ to 1.31$)$ & $1.11(0.92$ to 1.34$)$ \\
15 & $1.05(0.84$ to 1.31$)$ & $1.03(0.81$ to 1.30$)$ \\
$16+$ & $0.93(0.71$ to 1.22$)$ & $0.98(0.73$ to 1.31$)$ \\
p value & 0.713 & 0.753 \\
\hline
\end{tabular}

*Adjusted for sex, maternal education, maternal allergy history, maternal BMI (continuous).

menarche with increasing age in this sample did not differ significantly from the whole ALSPAC cohort; ${ }^{12} 41 \%$ of women reported reaching menarche before their 13th birthday and 98.7\% had reached menarche by their 17th birthday.

Table 1 shows the cumulative prevalence of each outcome and the distribution according to maternal age at menarche. To the age of 7 years, the prevalence of asthma ever was $20.4 \%$, eczema had been reported at least once in $58.6 \%$, hay fever was reported in $12.1 \%$, and $20.6 \%$ of the population had atopy as defined by a positive skin prick test response at 7 years. No significant trend in maternal age at menarche was evident for any of the outcomes considered. Table 1 also shows that the mean age of menarche (considered as a continuous variable) was not significantly different between mothers whose children had the outcome and those who did not. For doctor-diagnosed asthma, a higher proportion of mothers reported later menarche (16+ years) than at other ages $\left(p=0.01, \chi^{2}\right.$ test), although this did not reflect a consistent trend across age categories $\left(p_{\text {trend }}>0.5\right)$.

Tables 2-5 show the results of multivariable logistic regression analyses for each of the primary outcomes. Adjusted odds ratios were derived from multivariable models which included confounding variables that were statistically $(p<0.05)$ significantly associated with the outcome of interest in univariable analyses (data not shown, available on request). The results did not differ when all possible confounders were included in the final model, so only the former analyses are shown here. Confounders included in the adjusted analyses are given at the foot of each table.

There were no statistically significant associations between maternal age at menarche and atopy, eczema, or hay fever in their children by 7 years of age. A statistically significant association was observed for doctor-diagnosed asthma and increased age of menarche (OR 1.41 (95\% CI 1.00 to 1.99) for menarche onset at $16+$ years compared with the reference population (menarche $<12$ years, $\mathrm{p}=0.03$ ) that persisted after adjusting for possible confounders.

Table 4 Unadjusted and adjusted odds ratios for maternal age at menarche and hay fever

\begin{tabular}{lll}
\hline $\begin{array}{l}\text { Maternal age } \\
\text { at menarche } \\
\text { (years) }\end{array}$ & $\begin{array}{l}\text { Unadjusted OR (95\% Cl) } \\
\mathbf{n = 6 1 8 8}\end{array}$ & $\begin{array}{l}\text { Adjusted OR }(95 \% \mathrm{Cl}) \text { * } \\
\mathbf{n = 5 9 9 1}\end{array}$ \\
\hline$<12$ & 1.00 (reference) & 1.00 (reference) \\
12 & $1.00(0.79$ to 1.27$)$ & $1.05(0.82$ to 1.34$)$ \\
13 & $0.90(0.72$ to 1.13$)$ & $0.97(0.77$ to 1.23$)$ \\
14 & $1.00(0.78$ to 1.29$)$ & $1.08(0.84$ to 1.40$)$ \\
15 & $1.12(0.82$ to 1.51$)$ & $1.21(0.88$ to 1.66$)$ \\
$16+$ & $0.85(0.57$ to 1.28$)$ & $0.95(0.62$ to 1.44$)$ \\
p value & 0.678 & 0.750 \\
\hline
\end{tabular}

*Adjusted for sex, parity, maternal allergy history, and month of delivery.
Table 5 Unadjusted and adjusted odds ratios for maternal age at menarche and atopy defined by skin prick tests $(\geqslant 2 \mathrm{~mm})$

\begin{tabular}{lll}
\hline $\begin{array}{l}\text { Maternal age } \\
\text { at menarche } \\
\text { (years) }\end{array}$ & $\begin{array}{l}\text { Unadjusted OR }(95 \% \mathrm{Cl}) \\
\mathbf{n = 5 7 9 2}\end{array}$ & $\begin{array}{l}\text { Adjusted OR }(95 \% \mathrm{Cl} \text { )* } \\
\mathbf{n = 5 0 1 5}\end{array}$ \\
\hline$<12$ & 1.00 (reference) & 1.00 (reference) \\
12 & $0.95(0.77$ to 1.16$)$ & $0.93(0.75$ to 1.17$)$ \\
13 & $1.09(0.91$ to 1.31$)$ & $1.11(0.91$ to 1.37$)$ \\
14 & $0.90(0.72$ to 1.12$)$ & $0.89(0.71$ to 1.13$)$ \\
15 & $0.93(0.71$ to 1.22$)$ & $0.82(0.61$ to 1.11$)$ \\
$16+$ & $1.03(0.74$ to 1.44$)$ & $0.98(0.68$ to 1.42$)$ \\
$p$ value & 0.432 & 0.182 \\
\hline
\end{tabular}

*Adjusted for sex, maternal education, maternal age at delivery, parity, maternal allergy history, maternal smoking in pregnancy, maternal BMI (continuous), child birth weight (continuous), and skin prick tester.

\section{DISCUSSION}

Our study shows that, in a well characterised contemporary birth cohort, the offspring of mothers who had early onset of menarche did not develop asthma, eczema, hay fever or atopy (as measured by skin prick tests) during childhood more than infants of mothers with normal/late onset of menarche. The strengths of the present study were in the detailed classification of exposures, objective assessment of outcome variables, contemporary cohort of young children, and inclusion of a wide range of confounding variables. The change in the internal hormonal milieu associated with puberty and the personal use of contraceptives may theoretically modify the eventual expression of atopy in an individual. Moreover, smoking may be independently associated with asthma-like symptoms. Nevertheless, as we assessed atopy at the age of 7.5 years, this was unlikely to be confounded by such potential effect modifiers. The weaknesses were with self-reporting of asthma, eczema, and hay fever, along with the age of maternal menarche and maternal contraceptive usage, thereby potentially introducing bias. Nonetheless, the question was answered before the outcomes were assessed, so the response of women will not be influenced by knowledge of the outcome of the child. Furthermore, since atopy was assessed without the prior knowledge of maternal menarchal status, it is hard to envisage that this may have influenced our study.

Although we have not found a positive association between the age of onset of maternal menarche and the development of atopy in their offspring, there is biological plausibility for the relation of age of menarche with atopic outcomes. Early menarche has been linked to higher oestrogen levels and decreased serum sex hormone binding globulin that persists in adulthood and is an independent risk factor for breast cancer. ${ }^{13-}$ ${ }^{17}$ Epidemiological studies have shown a link between early menarche and intrauterine growth retardation in the offspring. ${ }^{18}$ Pregnancy is associated with strong skewing towards Th2 immunity and is thought to be secondary to evolutionary adaptation aimed at protecting the fetoplacental unit. ${ }^{19} 20$ Experimental evidence has suggested that a high maternal oestrogen level in pregnancy may be involved in fetal immunomodulation in favour of atopy by thymic atrophy, ${ }^{21}$ skewing towards a Th2 response, ${ }^{22}$ inhibition of $\mathrm{T}$ cell transmigration, ${ }^{23}$ and enhanced histamine release-mechanisms that may induce long lasting alterations in the $\mathrm{T}$ cell mediated immune responses in the offspring. ${ }^{24}$

Considerable methodological differences exist between this study and previous reports. Xu et al objectively assessed atopy in 5188 adults at 31 years of age. Their primary findings were that late onset of maternal menarche (beyond 16 years) was associated with a lower prevalence of atopy in these adult subjects, an effect that persisted mainly in 
women after adjusting for potential confounders. No such association was observed with asthma. The present study suggests a positive association with late menarche in mothers and asthma in their children, but only for those mothers with menarche onset at 16 years or later. This finding was not consistent across age categories and no significant difference in mean age of menarche was found between mothers whose children developed asthma and those who did not. This one finding therefore remains unexplained, is not consistent with the results of other analyses, and may represent a spurious observation.

$\mathrm{Xu}$ et al also reported a reduction in the mean age at menarche between the two generations studied from 14.1 years in mothers to 12.9 years in daughters, with a significant correlation between the age at menarche of mother and daughter. The age at menarche of the daughters was not, however, significantly associated with atopy although, like their mothers, there was a trend. However, this advancement in the age of menarche is in contrast with a recent observation in British teenagers where no such advancement was observed..$^{25}$ Furthermore, the long time interval between exposure and assessment of outcome may have led to unrecognised confounding that biased the results in favour of atopy. In addition, potential confounders such as the effect of smoking, puberty, personal contraceptive use, and prolonged exposure to allergens may also have skewed the results in favour of a positive outcome.

In contrast, a contemporary Danish study involved a large number of participants but lacked objective outcome measures as data were obtained by telephone interviews. ${ }^{10}$ The principal findings were that women who reached menarche before 12 years of age had a higher likelihood of developing allergic rhinitis with a significant trend. However, the cross sectional nature of the study makes interpretation of a causal relationship difficult.

In conclusion, in a contemporary birth cohort of prepubertal children no association was found between the maternal age at menarche and asthma, hay fever, eczema, or atopy in their offspring.

\section{ACKNOWLEDGEMENTS}

The whole ALSPAC Study Team comprises interviewers, computer technicians, laboratory technicians, clerical workers, research scientists, volunteers and managers, study parents, and the children who continue to make the study possible. The ALSPAC study is part of the WHO initiated European Longitudinal Study of Pregnancy \& Childhood (ELSPAC). Core funding for the long term follow up of the cohort has been mainly contributed by the Medical Research Council, the Wellcome Trust, the UK Department of Health, the Department of the Environment, DfEE, and the National Institutes of Health. The skin prick tests were funded in part by the British Lung Foundation.

\section{Authors' affiliations}

A Maitra, Department of Paediatric Medicine, Blackpool Royal Victoria Hospital, Blackpool FY3 8NR, UK

A Sherriff, K Northstone, Avon Longitudinal Study of Parents \& Children, University of Bristol, Division of Child Health, Bristol BS8 1TQ, UK
D Strachan, Community Health Sciences, St George's Hospital Medical School, London SW17 ORE, UK

A J Henderson, Department of Respiratory Medicine, Bristol Royal Hospital for Children, Bristol BS2 8BJ, UK

\section{REFERENCES}

1 Primatesta P. The health of young people 1995-1997. In: Primatesta P, eds. Health survey for England.Joint Health Surveys Unit. London: The Stationery Office, 1999.

2 National Asthma Campaign Asthma Audit. Out in the open. A true picture of asthma in the United Kingdom today. Asthma J 2001;6(Special Supplement).

3 International Study of Asthma, Allergies in Childhood (ISAAC). Worldwide variations in the prevalence of asthma symptoms. Eur Respir $J$ 1998; 12:315-35

4 International Study of Asthma and Allergies in Childhood (ISAAC) Steering Committee. Worldwide variation in prevalence of symptoms of asthma, allergic rhinoconjunctivitis, and atopic eczema: ISAAC. Lancet 1998;351:1225-32.

5 Woolcock AJ, Peat JK. Evidence for the increase in asthma worldwide. Ciba Foundation Symposium 1997;206:122-39.

6 von Mutius E. The rising trends in asthma and allergic disease. Clin Exp Allergy 1998;28(Suppl 5):45-51.

7 Doull IJ. Does pregnancy prevent atopy? Clin Exp Allergy 2001;31:1335-7.

8 Rangaraj S, Doull I. Hormones not hygiene? Birth order and atopy. Clin Exp Allergy 2003;33:277-8.

9 Xu B, Jarvelin MR, Hartikainen AL, et al. Maternal age at menarche and atopy among offspring at the age of 31 years. Thorax 2000;55:691-3.

10 Westergaard T, Begtrup K, Rostgaard K, et al. Reproductive history and allergic rhinitis among 31145 Danish women. Clin Exp Allergy 2003;33:301-5.

11 Xu B, Pekkanen J, Husman T, et al. Maternal sex hormones in early pregnancy and asthma among offspring: a case control study. J Allergy Clin Immunol 2003;112:1101-4.

12 Golding JPM, Jones R, ALSPAC Study Team. ALSPAC - The Avon Longitudinal Study of Parents and Children. I. Study methodology. Paediatr Perinat Epidemiol 2001;15:74-87.

13 Apter D, Bolton NJ, Hammond GL, et al. Serum sex hormone-binding globulin during puberty in girls and in different types of adolescent menstrual cycles. Acta Endocrinol 1984; 107:413-9.

14 Apter D, Vihko R. Early menarche, a risk factor for breast cancer, indicates early onset of ovulatory cycles. J Clin Endocrinol Metab 1983;57:82-6.

15 Apter D, Reinila M, Vihko R. Some endocrine characteristics of early menarche, a risk factor for breast cancer, are preserved into adulthood. Int J Cancer 1989;44:783-7.

16 Vihko R, Apter D. Endocrine characteristics of adolescent menstrual cycles: impact of early menarche. J Steroid Biochem 1984;20:231-6.

17 Vihko RK, Apter DL. The epidemiology and endocrinology of the menarche in relation to breast cancer. Cancer Surveys 1986;5:561-71.

18 Kirchengast S, Hartmann B. Association between maternal age at menarche and newborn size. Soc Biol 2000;47:1 14-26.

19 Bjorksten B. Allergy priming early in life. Lancet 1999;353:167-8.

20 Prescott SL, Macaubas C, Holt BJ, et al. Transplacental priming of the human immune system to environmental allergens: universal skewing of initial T cell responses toward the Th2 cytokine profile. J Immunol 1998; 160:4730-7.

21 Okasha SA, Ryu S, Do Y, et al. Evidence for estradiol-induced apoptosis and dysregulated $\mathrm{T}$ cell maturation in the thymus. Toxicology 2001;163:49-62.

22 Salem ML, Matsuzaki G, Kishihara K, et al. Beta-estradiol suppresses T cellmediated delayed-type hypersensitivity through suppression of antigenpresenting cell function and Th1 induction. Int Arch Allergy Immunol 2000;121:161-9.

23 Zang YC, Halder JB, Hong J, et al. Regulatory effects of estriol on T cell migration and cytokine profile: inhibition of transcription factor NF-kappa B. $J$ Neuroimmunol 2002;124:106-14.

24 Burke L, Segall-Blank $M$, Lorenzo $C$, et al. Altered immune response in adult women exposed to diethylstilbestrol in utero. Am J Obstet Gynecol $2001 ; 185: 78-81$

25 Whincup PH, Gilg JA, Odoki K, et al. Age of menarche in contemporary British teenagers: survey of girls born between 1982 and 1986. BMJ 2001;322:1095-6.

26 Viner R. Splitting hairs. Arch Dis Child 2002;86:8-10. 